\section{Reprogramming heart failure}

\section{By Kai-Jye Lou, Staff Writer}

Two groups at the University of California, San Francisco and The University of Texas Southwestern Medical Center have separately shown that delivering transcription factors directly to the heart reprogrammed cardiac fibroblasts and improved heart function in mouse models of post-myocardial infarction heart failure. ${ }^{1,2}$ Because the approach acts directly on endogenous cardiac cells, it could avoid the problems associated with transplanting exogenous cells to improve heart function.

LoneStar Heart Inc. has licensed the UT Southwestern technology.

In 2010, the UCSF lab led by Deepak Srivastava had shown in vitro that retrovirusmediated expression of three transcription factors-GATA binding protein 4 (Gata4), myocyte enhancer factor $2 \mathrm{C}(\mathrm{Mef} 2 \mathrm{c})$ and T-box 5 (Tbx5)-reprogrammed mouse cardiac fibroblasts into cells with a cardiomyocyte phenotype. ${ }^{3}$ They also showed that it was possible to transplant the reprogrammed cells
"The most interesting aspect of these studies-and where I think they could have the greatest impact-is in showing that you could regenerate the myocardium with the tissue that's already there."

- Patrick Most, Heidelberg University and others have suggested thymosin $\beta 4$ is cardioprotective and could promote cardiac repair and recovery of cardiac function. ${ }^{4-6}$

In its study, the UT Southwestern group showed that injecting the heart with a vector encoding GATA4, MEF2C and TBX5 plus a fourth transcription factor, heart and neural crest derivatives expressed 2 (HAND2), led to about fourfold more cardiomyocyte-like cells in vitro and quicker recovery of heart function in vivo than injection of a vector encoding only the original three transcription factors.

Results of both studies were published in Nature.

"The most interesting aspect of these studies-and where I think they could have the greatest impact-is in showing that you could regenerate the myocardium with the tissue that's already there," said Patrick Most, head of the Center for Molecular and Translational Cardiology at Heidelberg University.

\section{Replacing transplantation}

Having shown the feasibility of directly reprogramming endogenous cardiac fibroblasts into cardiomyocyte-like cells, the UCSF and UT Southwestern teams could bypass the challenges associated with cardiomyocyte transplantation.

Olson noted that the difficulties encountered with such therapies include transplanted cells "not engrafting efficiently, not surviving for the long term and not turning into heart muscle."

Coaxing endogenous cardiac fibroblasts to convert into myocytes "would be easier than trying to deliver cells to the heart," said Srivastava. "The endogenously generated myocytes would be more likely to integrate with the existing electrical and muscular into a mouse heart.

In the new studies, Srivastava's group at UCSF and Eric Olson's group at UT Southwestern have shown that it may be possible to avoid the transplantation step altogether by directly injecting the same transcription factors into the heart to trigger reprogramming of endogenous cardiac fibroblasts.

Srivastava is director of the Gladstone Institute of Cardiovascular Disease. He also is a professor in the Department of Pediatrics and the Department of Biochemistry \& Biophysics at UCSF. Olson is professor and chairman of the Department of Molecular Biology at UT Southwestern and cofounder and chief scientific advisor to LoneStar Heart.

In both studies, the groups boosted the activity of the original three transcription factors-GATA4, MEF2C and TBX5-by delivering them to the heart in combination with additional agents.

In a mouse model of myocardial infarction (MI), the UCSF group first showed that injecting a vector encoding Gata4, Mef2c and Tbx5 into the heart led to direct conversion of cardiac fibroblasts into cardiomyocytelike cells and improvement of cardiac function following injury.

The group then co-injected the same vector with thymosin $\beta 4$, which resulted in greater improvement of cardiac function in the mouse MI model than that seen using vector alone. Past studies led by Srivastava network of the heart than transplanted cells."

Moreover, cardiac fibroblasts "are present in excess in the heart and important for the initial phase of scar formation following injury. We thought that if even a small percentage of these cells could be repurposed to take on a myocyte role, we could enhance the function of injured hearts," said Olson.

Roger Hajjar, director of the Cardiovascular Research Center and a professor of medicine at Mount Sinai School of Medicine and a cofounder of Celladon Corp., said both groups' approaches provide a more direct pathway to generating cardiomyocytes.

"The route others have been using to generate these cells is first to turn fibroblasts into induced pluripotent stem cells and then to differentiate them into cardiomyocytes," but cells generated in this manner will still need to be transplanted, he told SciBX.

Celladon's Mydicar, a recombinant adeno-associated viral (AAV) vector carrying the gene for ATPase $\mathrm{Ca}^{++}$transporting cardiac muscle slow twitch 2 (SERCA2A; ATP2A2), has completed a Phase I/II study in patients with advanced heart failure. The gene is a regulator of myocardial contractility. 


\section{Fine-tuning expression}

Key challenges moving forward include restricting the effects of the vector to the heart and improving the vector's transduction efficiency.

"In our experience with localized delivery of adeno-associated viral vectors, we found that about $40 \%$ of the vector still leaves the heart and transfects other cells," Most told SciBX. Thus, the researchers will need to develop a way to control and restrict the expression of the vectorencoded genes to cardiac fibroblasts, he said.

Hajjar wanted to see further improvement in the vector's transduction efficiency, which on average was still under $10 \%$ based on the two papers.

"A higher transduction efficiency will probably be needed to convert a sufficient number of cardiac fibroblasts into myocytes that will then be able to support the activity and generation of additional myocytes," Hajjar told SciBX. "You would probably want transduction efficiencies to be in the $20 \%-30 \%$ range."

Srivastava said the UCSF group is not only moving forward with its gene therapy approach in porcine models but also starting to screen for small molecules and secreted proteins that could activate the same gene networks as those activated by the transcription factors.

The UT Southwestern group is now trying to elucidate the mechanisms that contribute to the observed effects in the mouse model and develop an optimized therapeutic protocol for testing in large animal models of heart failure.

The group has not yet decided whether it will move forward with the gene therapy approach or with some other therapeutic modality.

"Ideally one would like to identify drug-like small molecules that could upregulate expression of the four transcription factors," said Olson. "One might even consider combining such molecules with microRNAs to further improve the effect. This technology is still in its early days."

Olson is also cofounder and chief scientific advisor of miRNA company miRagen Therapeutics Inc.
UCSF and UT Southwestern have separately filed patents to cover the findings described in their respective papers.

LoneStar Heart has exclusive worldwide rights to the UT Southwestern technology and is using it to guide the development of the company's existing programs in restorative heart cell modulators and cellular and genetic therapies for advanced heart failure.

The UCSF patents are available for licensing.

Lou, K.-J. SciBX 5(22); doi:10.1038/scibx.2012.566

Published online May 31, 2012

\section{REFERENCES}

1. Qian, L. et al. Nature; published online April 18, 2012; doi:10.1038/nature11044

Contact: Deepak Srivastava, The J. David Gladstone Institutes, San Francisco, Calif. e-mail: dsrivastava@gladstone.ucsf.edu

2. Song, K. et al. Nature; published online May 13, 2012; doi:10.1038/nature11139

Contact: Eric N. Olson, The University of Texas Southwestern Medical Center, Dallas, Texas e-mail: eric.olson@utsouthwestern.edu

3. leda, M. et al. Cell 142, 375-386 (2010)

4. Bock-Marquette, l. et al. Nature 432, 466-472 (2004)

5. Hinkel, R. et al. Circulation 117, 2232-2240 (2008)

6. Smart, N. et al. Nature 474, 640-644 (2011)

\section{COMPANIES AND INSTITUTIONS MENTIONED}

Celladon Corp., La Jolla, Calif. Gladstone Institute of Cardiovascular Disease, San Francisco, Calif.

Heidelberg University, Heidelberg, Germany

LoneStar Heart Inc., Laguna Hills, Calif.

miRagen Therapeutics Inc., Boulder, Colo.

Mount Sinai School of Medicine, New York, N.Y. University of California, San Francisco, Calif. The University of Texas Southwestern Medical Center, Dallas, Texas 